\title{
Assessment of the clinical usefulness of ultrasound-guided cytological specimens obtained from gastrointestinal lesions in dogs and cats
}

\author{
R. B. S. Turner ${ }^{1}$, R. Liffman ${ }^{1}$, A.P. Woodward ${ }^{2}$, C. Beck ${ }^{1}$, N. Courtman ${ }^{1}$ and J. \\ R. S. Dandrieux ${ }^{1}$.
}

${ }^{1}$ U-Vet Animal Hospital, ${ }^{2}$ Faculty of Veterinary and Agricultural Sciences, University of Melbourne, 250 Princes Highway, Werribee, Victoria, 3030, Australia.

Corresponding author:
Robert Turner
BVSc MVS PGCertSci MANZCVS
Email: robert.turner@unimelb.edu.au

Tel: $\quad$ +61408163668

Authors Emails

R. Liffman

BVSc MVS MVSc MANZCVS Diplomate ACVP

Email: rebekah.liffman@unimelb.edu.au
A. Woodward
BVSc (Hons) BAnimSci PhD Diplomate ACVCP
Email: andrew.woodward@unimelb.edu.au
C. Beck
BVSc (Hons) MVS FANZCVS
Email: cbeck@unimelb.edu.au
N. Courtman
BVSc MVS MANZCVS DipACVP
Email: natalie.courtman@unimelb.edu.au

This is the author manuscript accepted for publication and has undergone full peer review but has not been through the copyediting, typesetting, pagination and proofreading process, which may lead to differences between this version and the Version of Record. Please cite this article as doi: $10.1111 /$ jsap. 13260

This article is protected by copyright. All rights reserved. 
$\begin{array}{ll}\text { J. Dandrieux } & \text { Dr med vet PhD DACVIM (SAIM) } \\ & \text { Email: julien.dandrieux@unimelb.edu.au }\end{array}$

Short Title:

Cytologic biopsy of gastrointestinal lesions

List of abbreviations

FNCB: fine-needle cytologic biopsy; GI: gastrointestinal; U-Vet: U-Vet Werribee Animal Hospital

Declarations

Ethics approval and consent to participate

Not applicable.

Consent for publication

Not applicable.

Availability of data and material

The data used and analysed during the current study are available from the corresponding author on reasonable request.

Competing interests 
The authors declare that they have no competing interests.

Funding

Not applicable.

Authors' contributions

$\mathrm{RT}, \mathrm{RL}, \mathrm{JD}$ were major contributors in experimental design, data acquisition, data interpretation and writing of the manuscript. NC was a major contributor to the data acquisition and critical analysis of the manuscript. AW and RT were major contributors to statistical analysis. $\mathrm{CB}$ and $\mathrm{AW}$ were significant contributors to data interpretation and critical analysis of the manuscript. All authors have read and approved the final manuscript.

Acknowledgements

I would like to express my gratitude to the U-Vet Werribee Animal Hospital for supporting this project.

\section{Word Count}

Abstract: 229 words

Article: $\quad 4384$ words

\section{Abstract}

This article is protected by copyright. All rights reserved. 


\section{$\underline{\text { Objectives }}$}

Cytological biopsies are an integral additional test to an abdominal ultrasound when a lesion is identified, but there is little published on factors that that may impact achieving a clinically useful sample of gastrointestinal (GI) lesions obtained by ultrasound-guided fine-needle cytologic biopsy (FNCB). This retrospective, descriptive study aimed to assess factors that may influence the clinical usefulness of submitted cytological samples collected from GI lesions by ultrasound-guided percutaneous FNCB.

\section{Material and Methods}

Gastrointestinal cytological samples obtained from 25 dogs and 19 cats over 2.5 years were reviewed and determined as clinically useful or clinically useless as per the cytology report. Variables dependent on the ultrasound exam that were used in the analysis included lesion location, lesion thickness, loss of gastrointestinal layering, and the number of slides submitted.

\section{$\underline{\text { Results }}$}

Thirty (30/44) of the submitted cytological samples were considered clinically useful. Factors associated with achieving a clinically useful sample in univariable models included the number of slides submitted and the thickness of the lesion. However, these two variables appear inter-related, as a weak correlation existed between them. Where histologic biopsies were obtained, a clinically useful sample had a partial or complete agreement with histology in 3/12 and 8/12 cases, respectively. 


\section{$\underline{\text { Clinical Relevance }}$}

Ultrasound-guided fine-needle cytological biopsies of gastrointestinal masses provided a clinically useful sample in two-third of the cases, especially if more slides were provided to the cytologist and thicker lesions were sampled.

$\underline{\text { Key Words }}$

Fine-needle cytologic biopsy, gastrointestinal, ultrasound, cytology. 


\section{Introduction}

For gastrointestinal (GI) cytological samples obtained by ultrasound-guided fine-needle cytologic biopsies (FNCB), there is a paucity of data on the factors that may impact the usefulness of the submitted sample. Fine-needle cytologic biopsies of abdominal lesions are commonly performed, and are perceived to be a rapid, useful, inexpensive, minimally invasive and relatively safe means of sampling (Papageorges et al 1988, Leveille et al 1993, Skeldon and Dewhurst 2009, Mattoon et al 2015). Fine-needle cytologic biopsies involve achieving a cellular sample for cytologic assessment by either fine needle aspiration (FNA) or fine-needle insertion (FNI) techniques (Lastra et al 2015, Mattoon et al 2015, Raskin 2018). There are many variables in achieving a clinically useful submitted cytological sample, with sufficient cell yield and preservation of cells to allow for at least a tentative cytological diagnosis of the lesion character or pathologic process (Sapierzyński et al 2017). These variables include disease factors (such as lesion location, lesion type, and lesion size); sampling variables in achieving a diagnostic yield (such as experience of sampling clinician, sampling technique (FNA vs FNI), needle size, slide preparation and number of passes), submission variables (such as macroscopic and microscopic assessment of slide preparation, number slides submitted and cover letter) and cytopathological variables (such as cytologist experience, cytologists certainty and stain preparation) (Dähnert et al 1992, Christopher and Hotz 2004, Erturk et al 2010, Marolf et al 2015, Inoue et al 2016, Sapierzyński et al 2017, Arai et 
al 2019). Sapierzyński et al. (2017) found that a clinically useful cytological sample was more likely if the lesion was superfical in location, and had good smear preparation. However this may vary with specific disease location and method of sampling, such as gastrointestinal (GI) lesions that are identified and sampled during a diagnostic abdominal ultrasound. Other variables may influence retrieval of a clinically useful sample from a GI lesion such as the use of ultrasound to guide the sampling, the sonographer's experience, lesion accessibility, lesion type, and lesion size. There is evidence to suggest deeper lesions may have reduced odds of achieving a clinically valuable result, compounding the moderate agreement between cytologic and histopathologic results (Bonfanti et al 2006, Sapierzyński et al 2017).

The data to date either studies cases with concomitant GI FNCB and histology (Bonfanti et al 2006) or factors affecting cytological yield from FNCB other than from GI masses (Sapierzynski et al 2017). However, when a GI lesion is detected on abdominal ultrasound, the clinician does not know what factors can help determine if an FNCB is likely to be of yield. For this reason, this study aimed to specifically assess factors that may influence the clinical usefulness of submitted cytological samples obtained from GI lesions by ultrasound-guided percutaneous FNCB.

\section{Materials and methods}

This article is protected by copyright. All rights reserved. 
This retrospective, single-institute, descriptive study reviewed GI cytologic samples obtained by ultrasound-guided FNCB of 25 dogs and 19 cats from February 2014 to August 2016. Cases were included if the ultrasound-guided FNCB and cytological evaluation were performed by a certified specialist or supervised residents in veterinary radiology and clinical pathology department, respectively. Cases were excluded if the location of the lesion could not be determined from the ultrasound report and records. Ultrasound-guided FNCB included a combination of FNI (non-aspiration) and FNA techniques, as the specific technique could not be determined retrospectively (Lastra et al 2015, Raskin 2018). Clinical records were evaluated to obtain historical data, clinical findings, diagnostic results and patient outcomes. The variables reviewed are defined in Appendix 1; with the primary outcome variable being whether or not a clinically useful cytologic sample was obtained. Immobilisation of the patient by sedation or general anaesthesia was performed for most patients, but not considered a variable as the time between immobilisation and sampling could not be determined from the records.

\section{Clinically Useful Cytologic Sample}

Each submitted cytologic sample was categorised as either clinically useful or clinically useless as previously defined (Sapierzyński et al 2017). Briefly, clinically useful samples were defined as smears with sufficient cell yield and preservation to allow at least a tentative cytological diagnosis of the lesion 
character or pathologic process. Clinically useless samples were defined as smears that were non-diagnostic with insufficient cell yield or insufficient cell preservation to allow even a tentative cytologic diagnosis. The cytological diagnosis was not assumed to be the clinical or histological diagnosis (see below).

Factors that may have influenced the retrieval of a clinically useful sample were assessed for and included in Appendix 1. Due to the retrospective nature of the study and small sample size, the primary variables assessed included lesion location (stomach, small intestine, ileocaecal junction and colon), sonographic lesion thickness, loss of or alteration to intestinal layer conspicuity on ultrasound (Figure 1), and the number of slides submitted to the cytologists. The thickness of the lesions were further categorised as either a mass $(\geq 20 \mathrm{~mm}$ thickness) or a thickening (<20mm). Other factors were considered but, as the information was rarely recorded, were not included in the analysis. These included the sampling technique (fine-needle insertion or fine-needle aspiration), needle size, and number of passes.

The primary pathologic process was recorded if determined. The pathologic process likely affects the retrieval of a clinically useful cytologic sample, but as the disease process is unknown at the time of sampling, it was considered relatively less important as it would not influence the choice to sample a lesion 
at the time of discovery. The predominant pathologic categorisation was determined as either normal (see cytological limitations below), inflammatory, neoplastic (malignant), or non-diagnostic based on the cytologists' or histopathologists' interpretation of the dominant disease process (Figure 2) (Bonfanti et al 2006). As cytology cannot reliably differentiate between normal, hyperplastic conditions, benign manifestations or well-differentiated malignant neoplasms, the appearance of 'normal cells' were categorised as 'cytologically normal', acknowledging this limitation. Additionally, further categorisation on the predominant cell population/lineage was performed, as either normal (see cytological limitations above), neutrophilic inflammation, lymphocytic inflammation, eosinophilic inflammation, histiocytic inflammation, mixed inflammation, round cell neoplasia, epithelial neoplasia, mesenchymal neoplasia, or undetermined neoplasia. When available, histology further categorised the predominant cell subtype (eg adenoma, adenocarcinoma versus carcinoma) (Bonfanti et al 2006).

\section{Cytologic Accuracy}

Accuracy of the cytology was not a primary focus of this study and has been assessed elsewhere (Bonfanti et al 2006). However, as accuracy of the cytologic interpretation affects the case management, if histopathology was available, the level of agreement between cytology and histology was determined using the histological diagnosis as the gold standard. The extent 
of agreement between the cytological and the histological diagnosis was categorised as complete agreement, partial agreement, no agreement, or undetermined (Bonfanti et al 2006). Complete agreement was defined as agreement in predominant pathological process and cell population. Partial agreement was defined as agreement concerning predominant pathologic process, but an inability to characterise the predominant cell population based on the cytologic examination. No agreement was defined as a lack of agreement in regard to predominant pathological process and cell population.

\section{Complications Related to Fine Needle Cytological Biopsies}

Complications related to FNCB were defined as any complications directly attributable to the procedure of FNCB. This included any records noted by the ultrasonographer (some sonographers record if any complications were noted during or after sampling), or within the patients' clinical records. Complications related to FNCB were categorised as either no, yes or not recorded.

\section{$\underline{\text { Clinical Direction }}$}

The case direction chosen by the owner and referring veterinarian after FNCB were mapped out and categorised into whether 'clinical management', ‘histologic biopsy' or ‘euthanasia-unrelated to GI lesion' was performed (Figure 3). Clinical management included clinical treatment (includes medical management, symptomatic or empirical management); or euthanasia-related to 
imaging and cytological findings. Although many factors influence case direction, analysis was limited to these factors due to the retrospective nature of the study.

\section{Data Analysis}

A clinically useful cytologic sample (0|1) was defined as the response variable in logistic regression models to determine the specific influence of the various predictors on the odds of a clinically useful outcome. The lesion size and the number of slides were log-transformed in all models. The log-transformation was selected as 1) those predictors were non-zero and non-negative, and 2) a log-linear relationship on the outcome was considered more realistic than a linear one. Candidate predictors were first evaluated by univariable screening to identify those that were associated with the outcome. Selected predictors were then introduced to a final multivariable model. Model optimization was performed using Firth logistic regression (Firth 1995) in the 'logistf' package (Heinze et al 2018) in R (R Core Team 2019). Goodness-of-fit of the models was determined using the $p$-value of the likelihood ratio test for the null model, and the Akaike's information criterion (AICc)(Hurvich and Tsai 1989). Uncertainty of the parameter estimates was described using 95\% confidence intervals, determined from the penalized profile likelihood (Cole et al 2014). Correlation between dataset variables was assessed using the Kendall's rank correlation (T).

This article is protected by copyright. All rights reserved. 


\section{Results}

A total of 1135 cytological submissions were collected over the study period. Of these, 81 samples were labelled as GI in origin, however after review of the cases, 29 were excluded as they were either not GI in origin (20), impression smears (3), or because of incomplete clinical records (6). After combining cases where repeat sampling was performed (8), a total of 44 GI FNCB cases were collected that met the inclusion criteria. This reflected $3.9 \%$ of cytological submissions to the institution over the 2.5 years study period. Samples had been taken from 25 dogs and 19 cats, with mean weight respectively of $19.6 \mathrm{~kg}$ (SD: $12.5 \mathrm{~kg}$, range: 2.8 to $50.3 \mathrm{~kg}$ ) and $4.5 \mathrm{~kg}$ (SD: $1.1 \mathrm{~kg}$, range: 2.3 to 7.0 $\mathrm{kg}$ ); and median age respectively of $12.2 \mathrm{yrs}$ (IQR: 9 to $14.3 \mathrm{yrs}$; range: 7.0 to $16.8 \mathrm{yrs}$ ) and $10.4 \mathrm{yrs}$ (IQR: 9.0 to $13.7 \mathrm{yrs}$; range: 5.6 to $16.0 \mathrm{yrs}$ ).

\section{Clinically Useful Cytologic Samples}

Thirty $(30 / 44 ; 68 \%)$ of the submitted cytological samples were considered clinically useful, including 11/18 from the stomach, 8/12 from the small intestine, $5 / 6$ from the ileocaecal junction, and 6/8 cases from the colon (Table 1). The mean lesion thickness and median number of submitted slides for a clinically useful cytological sample were $20.3 \mathrm{~mm}$ (SD: $21.3 \mathrm{~mm}$, range: 4.0 to $110.0 \mathrm{~mm}$ ) and 7 slides (IQR: 6 to 8; range: 2 to 14 slides); and for a clinically useless cytological sample were $9.8 \mathrm{~mm}$ (SD: $5.7 \mathrm{~mm}$, range: 3.2 to $22 \mathrm{~mm}$ ) and 4 slides 
(IQR: 3 to 6; range: 1 to 15 slides) (Figure 4). Of the clinically useful samples, 20/33 samples were considered to be thickenings; and 10/11 were considered to be masses (Table 1).

The lesion thickness $(\mathrm{mm})$ and number of submitted slides were significantly weakly positively correlated (т: $0.343, p=0.0021)$. In univariable logistic regression models with clinical usefulness $(0 \mid 1)$ as the response, the natural logarithm of lesion thickness $(\mathrm{mm})$ was positively associated $(\mathrm{OR}=3.43,95 \%$ Cl: 1.26-11.9) with odds of a clinically useful cytological sample, and the natural logarithm of number of submitted slides was positively associated (OR $=4.55$, 95\% Cl: 1.39-20.1) with odds of a clinically useful cytological sample (Table 2). In a multivariable logistic regression model containing natural logarithm both of lesion thickness and number of submitted slides as predictors, some evidence was obtained that both lesion thickness (OR=2.26, 95\% $\mathrm{Cl}: 0.76-8.36)$ and number of submitted slides $(\mathrm{OR}=2.65,95 \% \mathrm{Cl}$ : $0.76-12.4)$ were positively associated with odds of a clinically useful cytological sample, but the present data was insufficient to precisely elucidate the simultaneous effects (Table 2). The apparent collinearity between lesion thickness and submitted slide number suggests a limited capacity of the current data to indicate the relative importance of each of these predictors (Dormann et al 2013). A larger sample or a prospective study would be required to determine the role of each variable. 
The other variables assessed for an association with clinical usefulness are summarised in Table 1, and none were predictive.

Neoplasia was identified in $23 / 30$ cases (12/23 dogs and $11 / 23$ cats) with a mean lesion thickness of $22.2 \mathrm{~mm}$ (SD: $24.1 \mathrm{~mm}$, range: 4.0 to $110.0 \mathrm{~mm}$ ), inflammatory disease in 6/30 cases (5/6 dogs and $1 / 6$ cats) with a mean lesion thickness of $13.5 \mathrm{~mm}$ (SD: $8.0 \mathrm{~mm}$, range: 5.6 to 25.0 ), and normal cells in one case $(18.6 \mathrm{~mm})$. The stomach had 8/11 neoplastic cases (four sarcomas, three round cell, one carcinoma), two inflammatory samples (one histiocytic and one mixed inflammation) and normal cells in one case (dog). The small intestine had 7/8 cases considered neoplastic (four round cell, two carcinomas, one sarcoma) and only one inflammatory lesion (mixed inflammation with final diagnosis of toxoplasmosis) (Figure 2). The ileocaecal junction had 4/5 cases that were neoplastic (all round cell neoplasia) and one inflammatory lesion (neutrophilic). Four of the six (4/6) colonic lesions were neoplastic (one carcinoma, one round cell, one sarcoma, and one undetermined origin) and two were inflammatory (histiocytic and mixed).

\section{Histologic Biopsies and Cytological Accuracy}

A total of 17 histologic biopsies were performed, with 14 obtained surgically, 2 endoscopically and 1 at post-mortem. Biopsies were performed in 6/18 stomach lesion, 8/12 small intestinal lesions, 1/6 ileocaecal lesions, and 2/8 colon 
lesions. The mean lesion thickness for histologic biopsies was $20.9 \mathrm{~mm}$ (SD: $27.0 \mathrm{~mm}$ ); compared to lesions that were not biopsied (histologic) that had a mean thickness of $14.5 \mathrm{~mm}$ (SD: $10.5 \mathrm{~mm}$ ). Neoplasia was identified in 12/17 histologic biopsy cases (9/12 dogs and 3/12 cats) with a mean lesion thickness of $25.9 \mathrm{~mm}$ (SD: $30.7 \mathrm{~mm}$ ), inflammatory disease in 4/17 cases (1/4 dogs and $3 / 4$ cats) with a mean lesion thickness of $5.6 \mathrm{~mm}$ (SD: $2.5 \mathrm{~mm}$ ), and normal cells in 1 case $(22.0 \mathrm{~mm})$.

The cytologic disease classification of clinically useful sample agreed with the primary histological disease process in 11/12 cases (partial and complete agreement); and agreed with the predominant histological cell type in 8/12 cases (complete agreement) (Table 3).

\section{Complications Related to Fine Needle Cytological Biopsies}

No complications attributable to the FNCB were reported in the ultrasound report and clinical records (0/44; $95 \% \mathrm{Cl}$ : $0-0.018)$. However, only $7 / 44$ of the cases had a record of the absence of complications within the ultrasound report. Thus the finding may be an under-estimation of the true value.

\section{Clinical Direction}

The owner and clinician made a clinical decision without a histologic biopsy in 19/30 with clinically useful samples and in 9/14 cases with clinically useless 
samples (Figure 3). The owners elected to euthanise 6/30 patients with clinically useful cytological samples, whilst owners elected to euthanise 4/14 patients with clinically useless cytological samples. 


\section{Discussion}

Ultrasound-guided percutaneous FNCB appears moderately effective at retrieving clinically useful samples from GI lesions. The percentage of clinically useful cytological samples in our study (68\%) was lower than FNCB specific for GI neoplasia in another small animal study (82\% with 12/67 having unsatisfactory FNA cytologic samples) (Bonfanti et al 2006). It was however, comparable to small animal peritoneal/mesenteric disease (72.3\%) (Feeney et al 2013); small animal non-organ specific cytological submissions (59-80\%) (Skeldon and Dewhurst 2009, Sapierzyński et al 2017); and to human GI endoscopic fine needle aspirates (45-65\%) (Marco-Doménech et al 2001, Zhang et al 2016).

A clinically useful cytologic sample was used as the outcome variable as it represents the end-point of a multi-staged diagnostic process and all the variables leading to the final number of slides submitted to the cytologists. Variables that it includes are factors that may influence a diagnostic yield (such as sampling technique, needle size, number of passes) and how the slides were chosen for submission (such as slide preparation and macroscopic appearance). Due to the retrospective nature and relatively small sample size of this study, the influence of all the variables could not be individually determined. 
This study found that both increasing lesion thickness and number of slides submitted to the cytologists were positively associated with the odds of obtaining a clinically useful sample. These factors are apparently related ( $\mathrm{T}$ : 0.34), which is unsurprising, but the available data was insufficient to precisely estimate their combined effect (likely due to both the small sample size and influence of other factors). The relationship between the two variables has been observed in human endoscopic sampling, where GI lesions larger than 20mm had a diagnostic yield of $93 \%$ after one pass and $98 \%$ after two passes; whilst lesions less than $20 \mathrm{~mm}$ required three passes to achieve a yield of $77 \%$ (Inoue et al 2016). The relationship between lesion thickness and number of submitted slides likely indicates increased confidence in sampling larger lesions; increased urgency in achieving a diagnosis with larger lesions; or that larger lesions exfoliate more resulting in increased sampling. The use of numeric predictor variables in logistic regression analysis demanded that the shape of the relationship be specified; we selected a log-linear relationship for its better compatibility with the positively-constrained variables, rather than a linear relationship which was considered unrealistic. A detailed evaluation of the shape of these relationships would require substantially more data.

In the current study a clinically useful cytological sample was obtained with a median of seven submitted slides (range: 2-14). This may relate to the number of passes, but this was not recorded, and neither was the number of smears 
prepared from a single pass. This differs from a recent study of non-specific cytologic submissions that found that the number of submitted slides did not relate to a clinically useful result (Sapierzyński et al 2017). However, most samples in Sapierzyński study were not of Gl origin and mostly not obtained by ultrasound, limiting comparision. Further, there was no comment within the clinical records as to the gross appearance of the slide at preparation, and rapid on-site cytological assessment was not performed in our study, as this may improve the chance of a clinically useful cytological sample (Sapierzyński et al 2017).

Comparison to human literature is challenging, as the number of passes is usually reported (the number of attempts made to sample the lesion) and may occur with intra-procedural microscopic assessment of the sample cellularity (Inoue et al 2016). The number of passes for cytology of human lesions has questionable impact on achieving a diagnostic yield (Dähnert et al 1992, Inoue et al 2016). A minimum of three to four passes have been recommended in human literature to improve the chance of a diagnostic yield in abdominal cytology, with one pass achieving a diagnosis in $61-93 \%$ of cases, which increases to $74-98 \%$ with two passes, and $77-98 \%$ with three or more passes dependent on the location and lesion thickness (Dähnert et al 1992, Inoue et al 2016, Kobara et al 2017). The number of passes and its association with these 
other variables, or potential for increased complication should be ideally assessed in a prospective study.

The mean thickness of a diagnostic lesion in this study was $20.3 \mathrm{~mm}$ (SD: 21.5 $\mathrm{mm}$ ), with 10/30 clinically useful cytological samples greater than $20 \mathrm{~mm}$. This is in comparison to the clinically useless cytological samples with a mean thickness of $9.8 \mathrm{~mm}$ (SD: $5.7 \mathrm{~mm}$ ), with only one being greater than $20 \mathrm{~mm}$ (final diagnosis of gastric carcinoma). In human GI endoscopic samples, tissue was obtained from lesions less than $20 \mathrm{~mm}$ in $84 \%$ of the cases sampled and a cytologic diagnosis was achieved in $77 \%$ of the total number of cases sampled, while tissue and a diagnosis was obtained from lesions greater than $20 \mathrm{~mm}$ in $98 \%$ of cases (Inoue et al 2016). Small lesions may be more challenging to FNCB due to lesion access, operator experience, mobility of the lesion, inability to perform adequate excursion through the lesion, and less disruption of normal tissues architecture (Skeldon and Dewhurst 2009, Mattoon et al 2015, Sapierzyński et al 2017). Of note in the current study, clinically useful cytological samples were obtained from 6 lesions less than $8 \mathrm{~mm}$ (smallest $\sim 4 \mathrm{~mm}$ ), of which 3 were lymphoma. This suggests that useful information can be obtained in some instances from small lesions, and FNCB should not be limited to large lesions when the expertise to target such lesions is available. 
Needle size and the use of aspiration technique were not recorded in our study and, in the literature, have conflicting influence on obtaining a clinically useful cytological sample. A recent study that found the use of a $25 \mathrm{G}$ needle is as effective as a $22 \mathrm{G}$ in obtaining a diagnosis (Arai et al 2019). However, the use of the $25 \mathrm{G}$ needle was also associated with increased cell damage, and in a human study, an increased number of passes. The effect of needle size and use of negative-pressure should be evaluated in future research in regards to lesion size, access and vascularity, as well as specific pathology, patient comfort and post-operative complications.

The complete agreement between the FNCB cytological and histological results in this study (67\%) was similar to previously reported (64\%) (Bonfanti et al 2006). However, the partial-to-complete agreement (92\%) was higher than previously reported (72\%). This finding may represent a type 1 statistical error due to the small sample size, or could reflect the more detailed communication between submitting clinicians and the cyto-pathologist to reach a clinical outcome (Sharkey et al 2007). Other authors have also proposed the importance of communication with the cytologist in achieving a clinically useful result, with emphasis placed on the provision of medical history in a comprehensive cover letter (Christopher and Hotz 2004, Sapierzyński et al 2017).

This article is protected by copyright. All rights reserved. 
The ultrasound findings may also have provided some certainty to the diagnosis as the cytologists were not blinded of the sonographic findings. Though ultrasound is relatively non-specific, it may also offer diagnostic information, with GI neoplasms being more likely to have a thickness greater than $15 \mathrm{~mm}$ and loss of layering (Penninck et al 1990, Penninck et al 2003, Marolf et al 2015). Infering from our data, this was supported in our study, with neoplasia having an mean thickness of $22.2 \mathrm{~mm}$ (SD: $24.1 \mathrm{~mm}$ ) relative to inflammatory lesions mean thickness of $13.5 \mathrm{~mm}$ (SD: $8.0 \mathrm{~mm}$ ). However, the overlap in thickness between neoplastic and inflammatory lesions, and lack of further aetiologic specification, reinforces the value of GI FNCB or histologic biopsies over ultrasonographic appearance. Loss of layering was not specific to either neoplastic (18/23) and inflammatory (4/6) lesions, which was contradictory to other studies that found loss of layering to be highly predictive of neoplasia (Penninck et al 2003). This difference may be due to the lesions in our study having to be sufficiently large to show tissue disruption sonographically; some lesions being chronic in nature (4/6 were considered either mixed or histiocytic inflammation); and not being able to exclude neoplasia (1/6 cytologically inflammatory lesions was later diagnosed as a carcinoma on histology). Further, research is required to determine the importance of these and other factors (such as various imaging modilties in guiding sampling) on achieving a clinically useful sample. 
A clinical decision was made without a histologic biopsy in a majority of cases in our study (28/44). Though inference cannot be made, masses (mean: 20.9 $\mathrm{mm}$, SD: $27.0 \mathrm{~mm}$ ) were more likley to be biopsied for histology than thickened lesions (mean: $14.5 \mathrm{~mm}$, SD: $10.5 \mathrm{~mm}$ ). The greater number of thickenings (33/44 compared to 11/44 masses) and other variables such as owner compliance; pathologies preferentally medically treated (such as lymphoma); comorbidities; or presence or lack of lesional morbidities, such as GI obstruction or perforation may account for the lower number of cases that had histologic biopsies performed (7/9 lymphoma cases did not have biopsies). Though the relevance of each diagnostic test to the clinical outcome should be investigated further, clinicians may gain some confidence from the 25/30 samples deemed to be clinically useful that offered relevant information for guiding clinical decisions; and the reasonable agreement cytology had with histology. If partial and complete agreement are combined, the agreement with histology (92\%) is higher than previously reported for $\mathrm{GI}$ neoplasia (72\%) and similar to FNCB of other abdominal organs (84\%), though greater numbers are required to mitigate a false positive due to random effect (Leveille et al 1993, Bonfanti et al 2006).

Due to the retrospective nature of this paper and absence of defined observation, the safety of FNCB cannot be inferred from this study. However, no dogs died in the short-term period post FNCB and there were no recorded 
complications attributable to fine-needle biopsies within the study period. This is consistent with a single veterinary study where no complications were noted using a 22 G needle, and in a systematic human review of 10941 endoscopic ultrasound-guided FNCB, where a morbidity of $0.98 \%$ and mortality of $0.02 \%$ was noted (Penninck et al 1993, Wang et al 2011, de Sio et al 2013). This is lower than the complication rate of full-thickness surgical biopsies of GI lesions, recently reported as less than $3.5 \%$, and previously as high as $23 \%$ in veterinary medicine (Shales et al 2005, Swinbourne et al 2017).

As mentioned, the main limitation to this study was its retrospective nature and small sample size, and several factors were considered but could not be evaluated. Variables include the depth of and access to the lesion; the number of $\mathrm{Gl}$ lesions identified but not sampled (due to access or owner consent); regional lymphadenomegaly; number of passes (sampling attempts); length and gauge of needle used for the FNCB; whether aspiration or non-aspiration techniques were used; the gross or rapid/brief on-site cytological assessment of slide preparation; and the number of slides discarded after sampling the lesion. Further, the effects of lesion location (such as stomach or small intestine) and disease type (neoplastic or inflammatory subtype) on a clinically useful cytological sample were not statistically compared due to the low case numbers . The intrinsic property of specific disease processes may effect the diagnostic yield obtained by FNCB, with authors finding the sensitivity of FNA 
for mesenchymal tumours (eg leiomyoma and leiomyosarcomas) lower than lymphoma (Bonfanti et al 2006). Determing the influence of specific pathology in our study was not possible, due to the low sample size. Finally, the cytological and clinical diagnosis was not assumed to be the true diagnosis, unless histological biopsies were performed. However, the agreement with histology in our study was comparable to higher than previously published values (92\% compared to $72 \%$ had complete or partial agreement) (Bonfanti et al 2006). Further, determining the accuracy of GI FNCB was not the primary scope of this paper and has been previously investigated (Bonfanti et al 2006).

Ultrasound-guided fine-needle cytological biopsies of gastrointestinal lesions provided a clinically useful sample in two-third of the cases if sufficient cytological yield is achieved. The number of slides submitted to the cytologist and lesion thickness are both positively associated with attaining a clinically useful cytological sample, but the two variables are likely related, and their specific influence on retrieving a clinically useful sample could not be elucidated. Further research is required to determine the effect of other variables on achieving a clinically useful cytological sample from gastrointestinal lesions.

\section{Conflict of Interest}

No conflicts of interest have been declared 


\section{Reference:}

Arai, S., Rist, P., Clancey, N., et al. (2019) Fine-needle aspiration of cutaneous, subcutaneous, and intracavitary masses in dogs and cats using 22- vs 25-gauge needles. Veterinary Clinical Pathology 48, 287-292

Bonfanti, U., Bertazzolo, W., Bottero, E., et al. (2006) Diagnostic value of cytologic examination of gastrointestinal tract tumors in dogs and cats: 83 cases (2001-2004). Journal of the American Veterinary Medical Association 229, 1130-1133

Christopher, M. M. \& Hotz, C. S. (2004) Cytologic diagnosis: expression of probability by clinical pathologists. Veterinary Clinical Pathology 33, 8495

Cole, S. R., Chu, H. T. \& Greenland, S. (2014) Maximum Likelihood, Profile Likelihood, and Penalized Likelihood: A Primer. American Journal of Epidemiology 179, 252-260 
Dähnert, W. F., Hoagland, M. H., Hamper, U. M., et al. (1992) Fine-needle aspiration biopsy of abdominal lesions: diagnostic yield for different needle tip configurations. Radiology 185, 263-268

de Sio, I., Funaro, A., Vitale, L. M., et al. (2013) Ultrasound-guided percutaneous biopsy for diagnosis of gastrointestinal lesions. Digestive and Liver Disease 45, 816-819

Dormann, C. F., Elith, J., Bacher, S., et al. (2013) Collinearity: a review of methods to deal with it and a simulation study evaluating their performance. Ecography 36, 27-46

Erturk, S. M., Silverman, S., Mortele, K., et al. (2010) Percutaneous biopsy of abdominal masses using 25-gauge needles. Abdominal Imaging 35, 7074

Feeney, D. A., Ober, C. P., Snyder, L. A., et al. (2013) Ultrasound criteria and guided fine-needle aspiration diagnostic yields in small animal peritoneal, mesenteric and omental disease. Veterinary Radiology \& Ultrasound 54, 638-645

Firth, D. (1995) Bias reduction of maximum-likelihood-estimates. Biometrika $82,667-667$ 
Heinze, G., Ploner, M., Dunkler, D., et al. (2018) Package 'logistf', 1.23:

http://cemsiis.meduniwien.ac.at/en/kb/scienceresearch/software/statistical-software/fllogistf/

Hurvich, C. M. \& Tsai, C.-L. (1989) Regression and time series model selection in small samples. Biometrika 76, 297-307

Inoue, T., Okumura, F., Mizushima, T., et al. (2016) Assessment of Factors Affecting the Usefulness and Diagnostic Yield of Core Biopsy Needles with a Side Hole in Endoscopic Ultrasound-Guided Fine-Needle Aspiration. Gut and Liver 10, 51-57

Kobara, H., Mori, H., Nishimoto, N., et al. (2017) Comparison of submucosal tunneling biopsy versus EUS-guided FNA for gastric subepithelial lesions: a prospective study with crossover design. Endoscopy International Open 5, 695-705

Lastra, R. R., Pramick, R. M. \& Baloch, Z. W. (2015) Fine-needle aspiration biopsy techniques. In: Comprehensive cytopathology, Fourth edition edn. Elsevier Saunders

Leveille, R., Partington, B. P., Biller, D. S., et al. (1993) Complications after ultrasound-guided biopsy of abdominal structures in dogs and cats - 
246 cases (1984-1991). Journal of the American Veterinary Medical Association 203, 413-415

Marco-Doménech, S. F., Gil-Sánchez, S., Fernández-García, P., et al. (2001) Sonographically Guided Percutaneous Biopsy of Gastrointestinal Tract Lesions. American Journal of Roentgenology 176, 147-151

Marolf, A. J., Bachand, A. M., Sharber, J., et al. (2015) Comparison of endoscopy and sonography findings in dogs and cats with histologically confirmed gastric neoplasia. Journal of Small Animal Practice 56, 339344

Mattoon, J. S., Pollard, R. E., Wills, T., et al. (2015) Ultrasound-Guided Aspiration and Biopsy Procedures. In: Small animal diagnostic ultrasound, Third edition edn. Eds J. S. Mattoon and T. G. Nyland. St. Louis, Missouri : Elsevier, [2015]. pp 50-77

Papageorges, M., Gavin, P., Sande, R., et al. (1988) Ultrasound-guided fineneedle aspiration - an inexpensive modification of the technique. Veterinary Radiology 29, 269-271

Penninck, D., Smyers, B., Webster, C. R. L., et al. (2003) Diagnostic value of ultrasonography in differentiating enteritis from intestinal neoplasia in dogs. Veterinary Radiology \& Ultrasound 44, 570-575 
Penninck, D. G., Crystal, M. A., Matz, M. E., et al. (1993) The technique of percutaneous ultrasound-guided fine-needle aspiration biopsy and automated microcore biopsy in small animal gastrointestinal-diseases. Veterinary Radiology \& Ultrasound 34, 433-436

Penninck, D. G., Nyland, T. G., Kerr, L. Y., et al. (1990) Ultrasonographic evaluation of gastrointestinal-diseases in small animals. Veterinary Radiology 31, 134-141

R Core Team (2019) R: A Language and Environment for Statistical Computinghttp://www.R-project.org/

Raskin, R. E. (2018) When is an aspirate a biopsy? Always! Veterinary and Comparative Oncology 16, 170-170

Sapierzyński, R., Czopowicz, M. \& Ostrzeszewicz, M. (2017) Factors affecting the diagnostic utility of canine and feline cytological samples. Journal of Small Animal Practice 58, 73-78

Shales, C. J., Warren, J., Anderson, D. M., et al. (2005) Complications following full-thickness small intestinal biopsy in 66 dogs: a retrospective study. Journal of Small Animal Practice 46, 317-321

This article is protected by copyright. All rights reserved. 
Sharkey, L. C., Dial, S. M. \& Matz, M. E. (2007) Maximizing the Diagnostic Value of Cytology in Small Animal Practice. Veterinary Clinics of North America: Small Animal Practice 37, 351-372

Skeldon, N. \& Dewhurst, E. (2009) The perceived and actual diagnostic utility of veterinary cytological samples. Journal of Small Animal Practice 50, 180-185

Swinbourne, F., Jeffery, N., Tivers, M. S., et al. (2017) The incidence of surgical site dehiscence following full-thickness gastrointestinal biopsy in dogs and cats and associated risk factors. Journal of Small Animal Practice 58, 495-503

Wang, K.-X., Ben, Q.-W., Jin, Z.-D., et al. (2011) Assessment of morbidity and mortality associated with EUS-guided FNA: a systematic review. Gastrointestinal Endoscopy 73, 283-290

Zhang, X. C., Li, Q. L., Yu, Y. F., et al. (2016) Diagnostic efficacy of endoscopic ultrasound-guided needle sampling for upper gastrointestinal subepithelial lesions: a meta-analysis. Surg Endosc 30, 2431-2441

Figure 1: Ultrasound images of lesions sampled for cytology. 
A: Transverse plane image of the jejunum of a dog with thickening of the muscularis layer but maintenance of intestinal wall layering

B: (Oblique) transverse plane image of the stomach of a cat with reduced layer conspicuity

C: Longitudinal plane image of the stomach of a cat with loss of layering

D: Longitudinal plane image of the colon of a dog with loss of layering

Figure 2: Fine needle cytologic biopsy smears, stained with Wright's Giemsa. A: Intestine, inflammatory lesion: Neutrophil rich mixed inflammation. Numerous neutrophils, lymphocytes and macrophages with occasional extracellular (black arrows) and intracellular (red arrow) protozoa (Toxoplasma sp.) in a proteinaceous background containing blood.

B: Intestine, neoplastic lesion: Large cell lymphoma. Numerous large lymphocytes with fine cytoplasmic vacuolation amidst free nuclei, cytoplasmic fragments, in a proteinaceous background containing blood.

C: Stomach, neoplastic lesion: Carcinoma. Clump of large epithelial cells demonstrating criteria of malignancy (cytomegaly, karyomegaly, high nuclear:cytoplasmic ratio, anisonucleolosis, macronucleoli) in a light proteinaceous background containing blood.

Figure 3: Case direction algorithm of cytological biopsies from the gastrointestinal tract in 25 dogs and 19 cats. 
Figure 4: Dot plots overlaid box-and-whisker plots of the lesion thickness (A) and the number of slides (B) and their relationship in obtaining a clinically useful cytological sample. The y-axes are in logarithmic scale. 


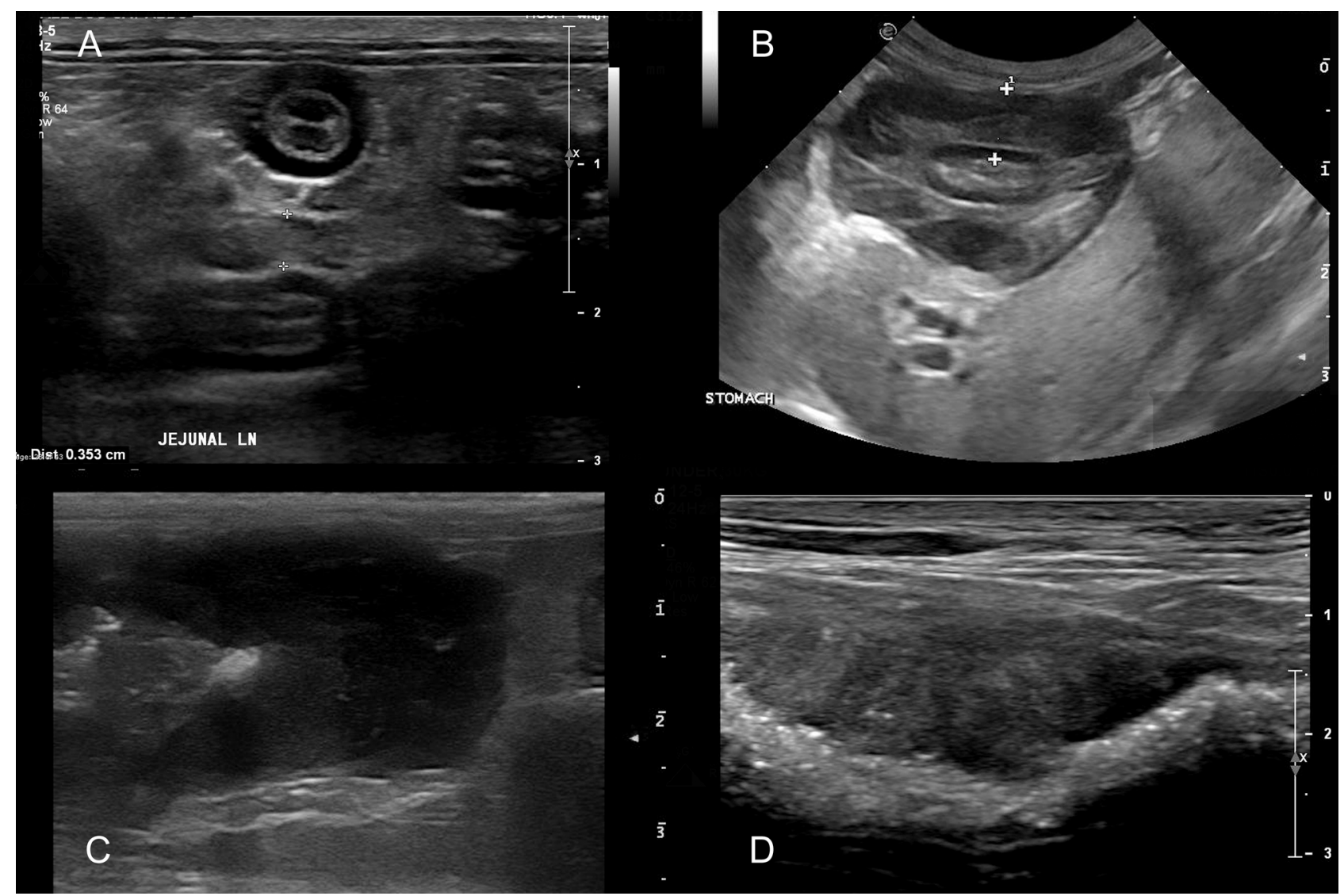

JSAP_13260_Figure 1.tif

This article is protected by copyright. All rights reserved. 


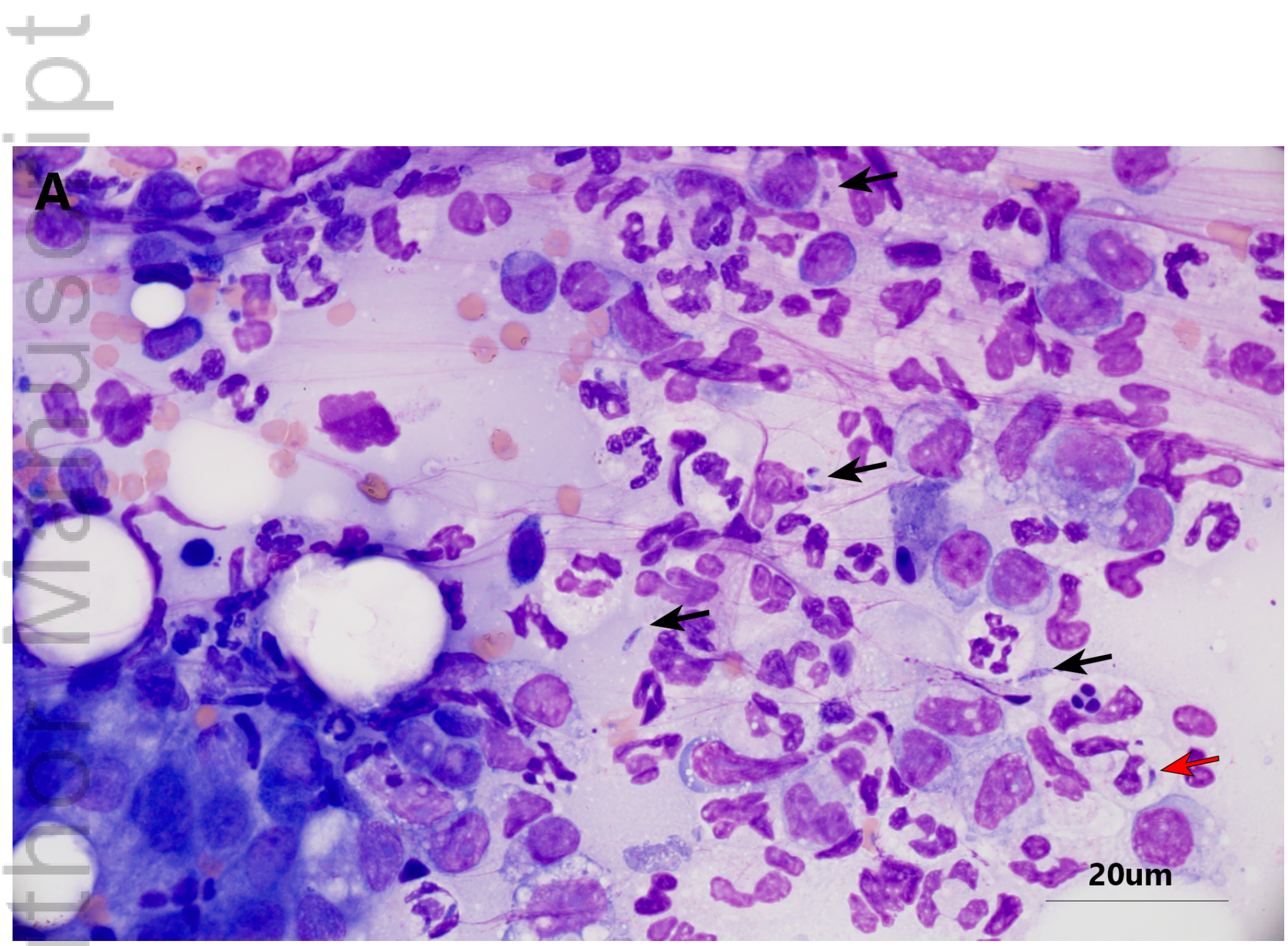

JSAP_13260_Figure 2A.tiff 


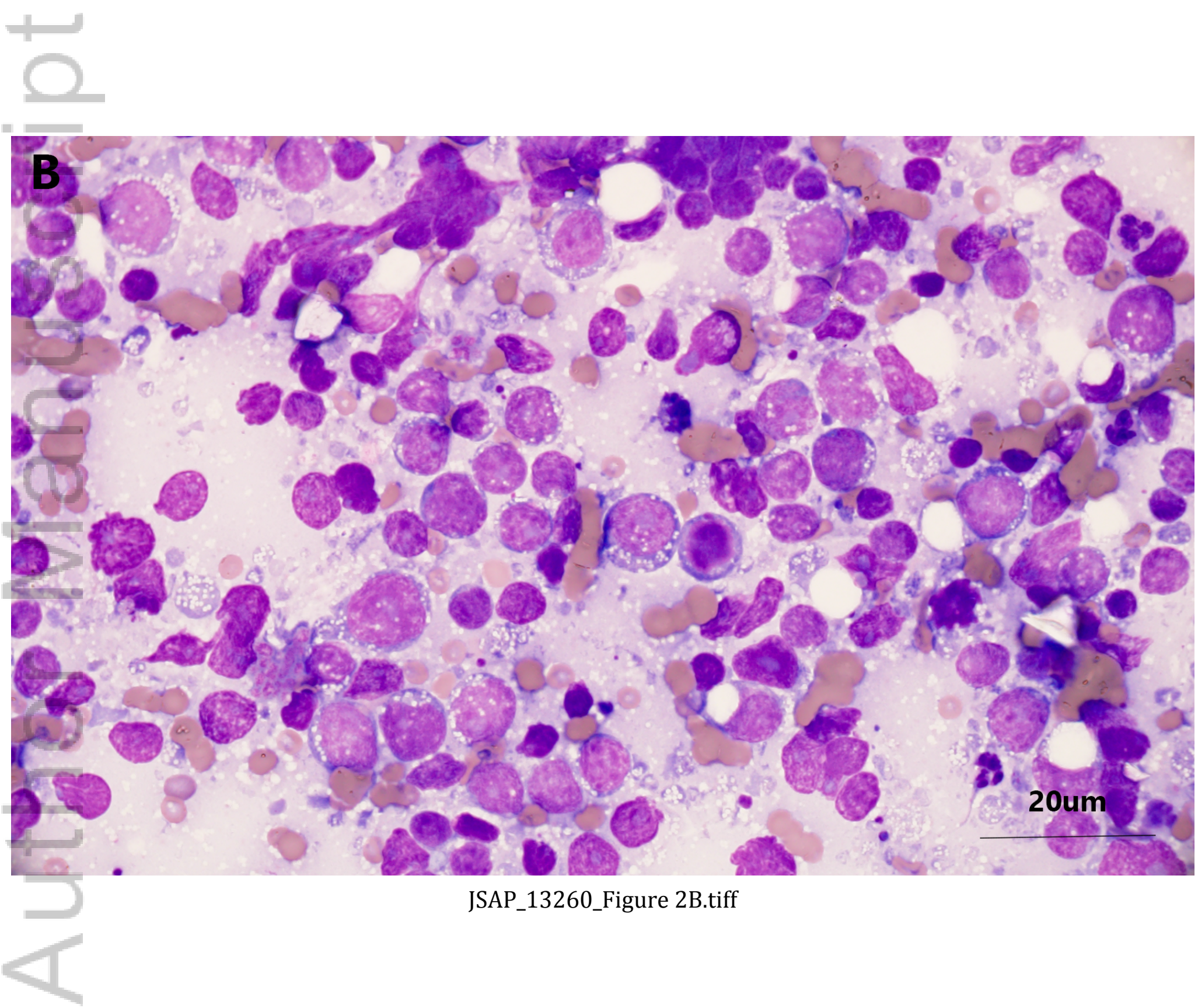

This article is protected by copyright. All rights reserved. 


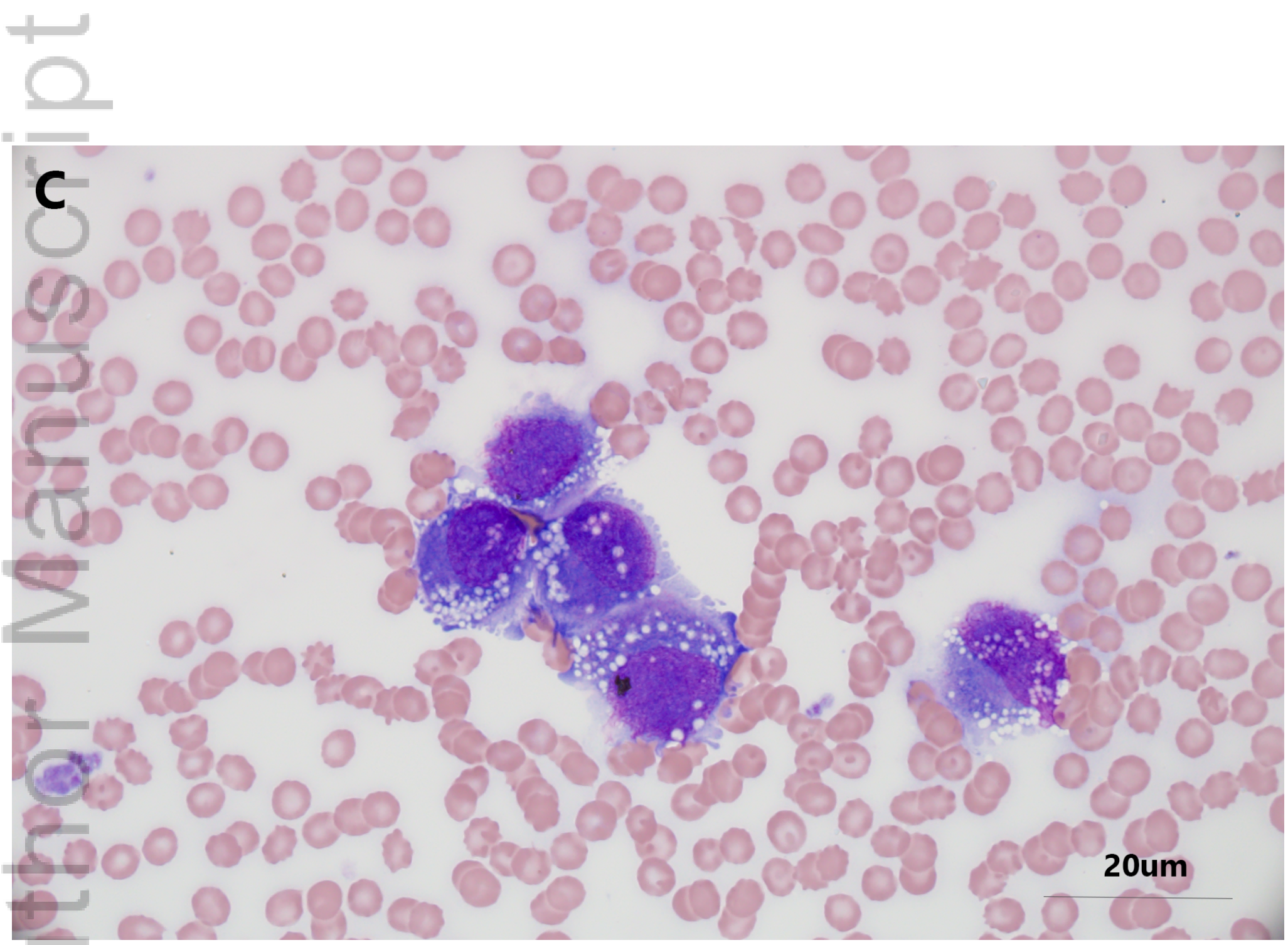

JSAP_13260_Figure 2C.tiff 


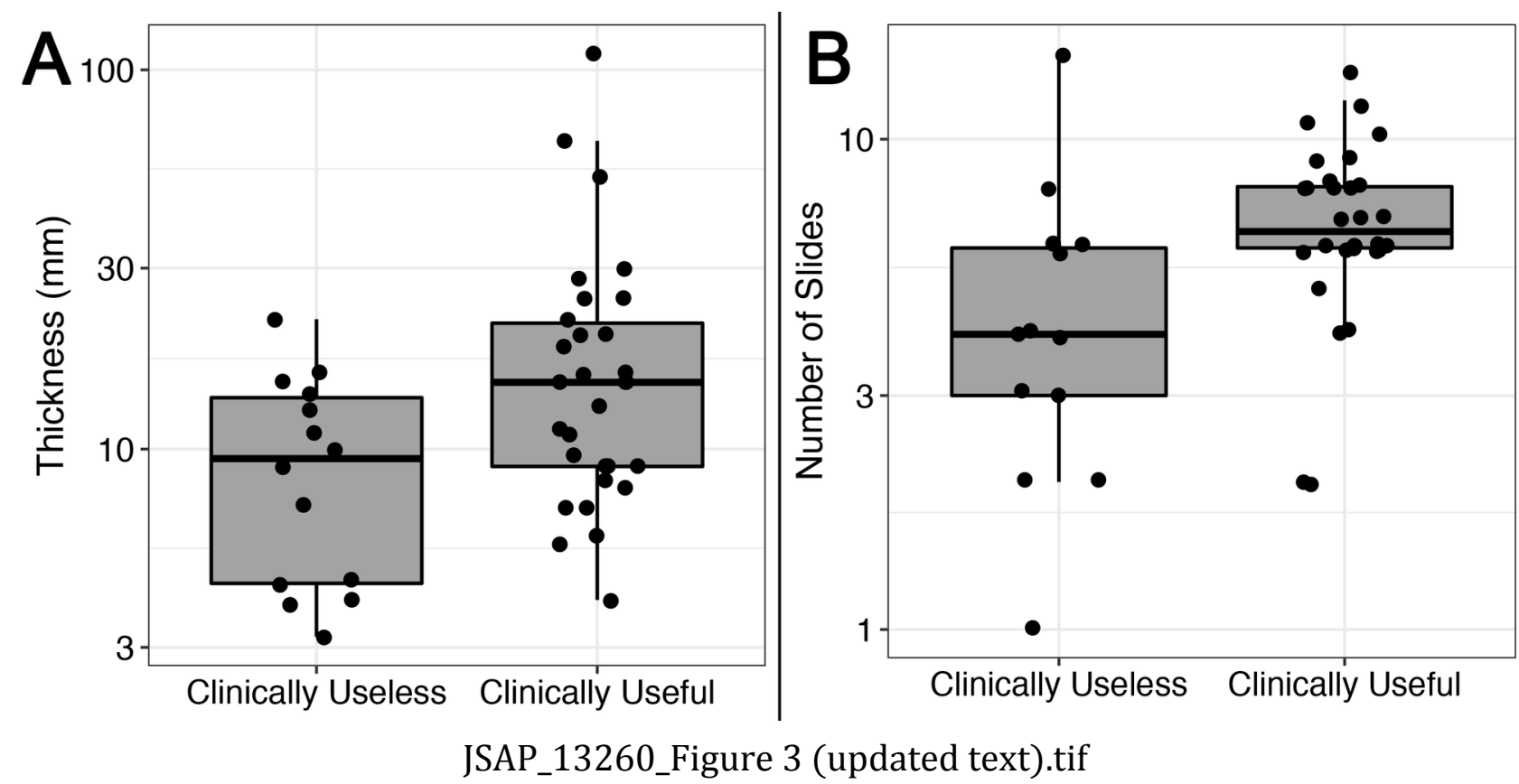

This article is protected by copyright. All rights reserved. 


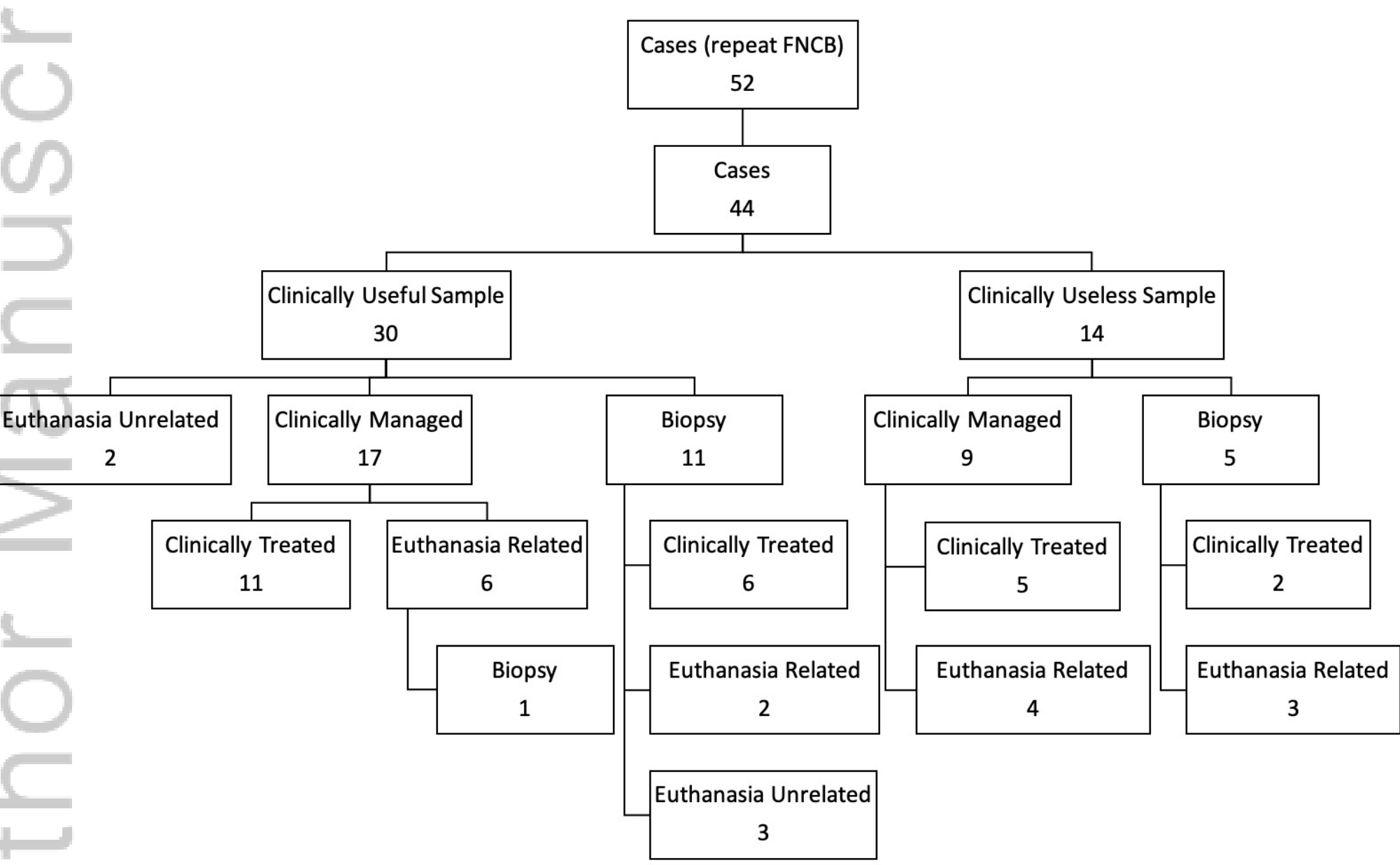

JSAP_13260_Figure 4 (text 14 updated) copy.tiff

This article is protected by copyright. All rights reserved. 
Table 1: Observed variables that may influence the retrieval of a clinically useful sample

\begin{tabular}{|c|c|c|c|c|c|c|c|c|}
\hline \multirow[t]{2}{*}{ Observed Variable } & \multirow[t]{2}{*}{ Category } & \multicolumn{3}{|c|}{ Clinically Useful Samples } & \multicolumn{3}{|c|}{ Clinically Useless Samples } & \multirow{2}{*}{$\begin{array}{l}\text { Total } \\
\mathrm{n}\end{array}$} \\
\hline & & Mean & SD & $\mathrm{n}$ & Mean & & $\mathrm{n}$ & \\
\hline Species & $\begin{array}{l}\text { Dog } \\
\text { Cat }\end{array}$ & & & $\begin{array}{l}18 \\
12\end{array}$ & & & $\begin{array}{l}7 \\
7\end{array}$ & $\begin{array}{l}25 \\
19\end{array}$ \\
\hline Age (years) & & 12.0 & & & 11.1 & & & \\
\hline Weight $(\mathrm{kg})$ & $\begin{array}{l}\text { Dog } \\
\text { Cat }\end{array}$ & $\begin{array}{l}19.8 \\
4.5\end{array}$ & $\begin{array}{l}13.4 \\
0.9\end{array}$ & & $\begin{array}{l}19.0 \\
4.6\end{array}$ & $\begin{array}{l}10.9 \\
1.5\end{array}$ & & \\
\hline Presentation & $\begin{array}{l}\text { GI } \\
\text { Non-GI }\end{array}$ & & & $\begin{array}{l}24 \\
6 \\
\end{array}$ & & & $\begin{array}{l}13 \\
1\end{array}$ & \\
\hline Location & $\begin{array}{l}\text { Stomach } \\
\text { Small Intestine } \\
\text { lleocaecal Junction } \\
\text { Colon }\end{array}$ & & & $\begin{array}{l}11 \\
8 \\
5 \\
6\end{array}$ & & & $\begin{array}{l}7 \\
4 \\
1 \\
2\end{array}$ & $\begin{array}{l}18 \\
12 \\
6 \\
8\end{array}$ \\
\hline $\begin{array}{l}\text { Intestinal Layer } \\
\text { Visibility }^{1}\end{array}$ & $\begin{array}{l}\text { Visible layers } \\
\text { Loss of layering }\end{array}$ & & & $\begin{array}{l}5 \\
23 \\
\end{array}$ & & & $\begin{array}{l}4 \\
9 \\
\end{array}$ & $\begin{array}{l}9 \\
32 \\
\end{array}$ \\
\hline Mass or Thickening & $\begin{array}{l}\text { Thickening }(<20 \mathrm{~mm} \\
) \\
\text { Mass }(\geq 20 \mathrm{~mm})\end{array}$ & & & $\begin{array}{l}20 \\
10\end{array}$ & & & $\begin{array}{l}13 \\
1\end{array}$ & $\begin{array}{l}33 \\
11\end{array}$ \\
\hline $\begin{array}{l}\text { Lesion thickness } \\
(\mathrm{mm})\end{array}$ & $\begin{array}{l}\text { Overall }^{2} \\
\text { Neoplasia } \\
\text { Inflammation } \\
\text { Normal Cell }^{3} \\
\end{array}$ & \begin{tabular}{|l|}
20.3 \\
22.2 \\
13.5 \\
18.6 \\
\end{tabular} & $\begin{array}{l}21.5 \\
24.1 \\
8.0\end{array}$ & $\begin{array}{l}30 \\
23 \\
6 \\
1 \\
\end{array}$ & 9.8 & 5.7 & 14 & \\
\hline & & Median & Range & $\mathrm{n}$ & Median & Range & $\mathrm{n}$ & \\
\hline $\begin{array}{l}\text { Number of slides } \\
\text { submitted }\end{array}$ & $\begin{array}{l}\text { Overall }^{4} \\
\text { Neoplasia } \\
\text { Inflammation }\end{array}$ & $\begin{array}{l}7 \\
7 \\
7\end{array}$ & $\begin{array}{l}2-14 \\
2-14 \\
2-11\end{array}$ & $\begin{array}{l}30 \\
23 \\
6\end{array}$ & 4 & $1-15$ & 14 & \\
\hline
\end{tabular}




\begin{tabular}{|l|l|l|l|l|} 
& Normal Cell & 6 & 1 & 5 \\
\\
\hline Tissue Biopsy & Yes & 12 & 18 & 17 \\
& No & 18 & 9 & 27 \\
\hline
\end{tabular}

1. Three cases did not have data recorded

2. Lesion thickness $(\mathrm{mm})$ was positively associated (OR=3.43, 95\% Cl: 1.26-11.9) with odds of a diagnostic sample

3. Normal on cytology but diagnosed as a sarcoma on histology

4. Number of slides obtained was positively associated (OR=4.55, 95\% Cl: 1.39-20.1) with odds of a diagnostic sample 


\begin{tabular}{|l|l|l|l|l|c|}
\hline Model & Predictor & $\begin{array}{c}\text { Coefficient } \\
\text { Estimate }\end{array}$ & $\begin{array}{c}\text { Odds Ratio } \\
\text { Estimate }\end{array}$ & $\begin{array}{c}95 \% \\
\text { Confidence } \\
\text { Interval }\end{array}$ & $p$-value \\
\hline A & num_slides & 1.52 & 4.55 & $1.39-20.1$ & 0.0110 \\
\hline B & thickness & 1.23 & 3.43 & $1.26-11.9$ & 0.0136 \\
\hline C & num_slides & 0.974 & 2.65 & $0.760-12.4$ & 0.129 \\
& & & & & 0.149 \\
\cline { 2 - 6 } & thickness & 0.814 & 2.26 & $0.763-8.36$ & \\
\hline & & & & & \\
\hline
\end{tabular}

Table 2: Parameter estimates from candidate penalized logistic regression models for the probability of a diagnostic sample ('diagnostic'), $n=44$, as a function of the number of slides submitted to the clinical pathologist ('num_slides') or the lesion thickness (mm; 'thickness'). Coefficient estimate: the estimated value of the parameter for this predictor variable. Odds Ratio Estimate: estimated change in odds of diagnostic sample with a one-unit (in logarithmic space) increase in the predictor variable value. $95 \%$ confidence intervals are expressed in the space of the odds ratio. $p$-values are for the test hypothesis of value 0 for the coefficient (odds ratio 1). Model used: A: logit(diagnostic) $1+$ $\log _{\mathrm{e}}\left(\right.$ num_slides); B: logit(diagnostic) $~ 1+\log _{\mathrm{e}}$ (thickness); C: logit(diagnostic) $\sim 1+\log _{\mathrm{e}}$ (num_slides) $+\log _{\mathrm{e}}$ (thickness). 
Table 3: Level of agreement between cytological and histological diagnosis

\begin{tabular}{|c|c|c|c|c|}
\hline $\begin{array}{c}\text { Level of } \\
\text { Agreement }\end{array}$ & $\begin{array}{c}\text { Count } \\
\text { n }\end{array}$ & $\begin{array}{l}\text { Thickness } \\
\text { (mm) } \\
\text { Mean (SD) }\end{array}$ & Cytological Diagnosis & Histological Diagnosis \\
\hline Un-determined & 5 & $9.6(8.2)$ & Clinically useless sample & $\begin{array}{l}\text { Mixed inflammatory (2) } \\
\text { Round Cell (lymphoma) (1) } \\
\text { Carcinoma (1) } \\
\text { Normal (1) }\end{array}$ \\
\hline No Agreement & 1 & 18.6 & Normal Cells (epithelial) & Sarcoma (leiomyosarcoma) (1) \\
\hline Partial & 3 & $11.0(7.8)$ & $\begin{array}{l}\text { Round cell (undefined) } \\
\text { Mixed neoplasia } \\
\text { Inflammatory }\end{array}$ & $\begin{array}{l}\text { Round cell (lymphoma) } \\
\text { Carcinoma } \\
\text { Lymphoplasmacytic Inflammatory }\end{array}$ \\
\hline Complete & 8 & $32.0(36.5)$ & $\begin{array}{l}\text { Round cell (2) } \\
\text { Carcinoma (2) } \\
\text { Sarcoma (3) } \\
\text { Mixed Inflammatory }\end{array}$ & $\begin{array}{l}\text { Round cell (2) } \\
\text { Carcinoma (2) } \\
\text { Sarcoma (3) } \\
\text { Mixed Inflammatory }\end{array}$ \\
\hline
\end{tabular}

This article is protected by copyright. All rights reserved. 


\begin{tabular}{|l|r|r|l|l|}
\hline Total & 17 & $20.9(27.0)$ & & \\
\hline
\end{tabular}


Assessment of the clinical usefulness of ultrasound-guided cytological specimens obtained from gastrointestinal lesions in dogs and cats

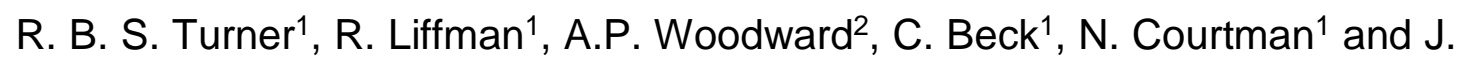
R. S. Dandrieux ${ }^{1}$.

${ }^{1}$ U-Vet Animal Hospital, ${ }^{2}$ Faculty of Veterinary and Agricultural Sciences, University of Melbourne, 250 Princes Highway, Werribee, Victoria, 3030, Australia.

Corresponding author:

Robert Turner $\quad$ BVSc MVS PGCertSci MANZCVS

Email: robert.turner@unimelb.edu.au

Tel: $\quad+61408163668$

$\underline{\text { Authors Emails }}$

R. Liffman $\quad$ BVSc MVS MVSc MANZCVS Diplomate ACVP Email: rebekah.liffman@unimelb.edu.au

A. Woodward $\quad$ BVSc (Hons) BAnimSci PhD Diplomate ACVCP

Email: andrew.woodward@unimelb.edu.au

C. Beck

BVSc (Hons) MVS FANZCVS

Email: cbeck@unimelb.edu.au

N. Courtman $\quad$ BVSc MVS MANZCVS DipACVP

Email: natalie.courtman@unimelb.edu.au

J. Dandrieux Dr med vet PhD DACVIM (SAIM)

Email: julien.dandrieux@unimelb.edu.au 
Short Title:

Cytologic biopsy of gastrointestinal lesions

List of abbreviations

FNCB: fine-needle cytologic biopsy; GI: gastrointestinal; U-Vet: U-Vet Werribee Animal Hospital

Declarations

Ethics approval and consent to participate

Not applicable.

Consent for publication

Not applicable.

Availability of data and material

The data used and analysed during the current study are available from the corresponding author on reasonable request.

Competing interests

The authors declare that they have no competing interests.

Funding

Not applicable.

Authors' contributions

This article is protected by copyright. All rights reserved. 
$\mathrm{RT}, \mathrm{RL}, \mathrm{JD}$ were major contributors in experimental design, data acquisition, data interpretation and writing of the manuscript. NC was a major contributor to the data acquisition and critical analysis of the manuscript. AW and RT were major contributors to statistical analysis. $\mathrm{CB}$ and $\mathrm{AW}$ were significant contributors to data interpretation and critical analysis of the manuscript. All authors have read and approved the final manuscript.

\section{Acknowledgements}

I would like to express my gratitude to the U-Vet Werribee Animal Hospital for supporting this project. 